\title{
Iatrogenic Disruption of Left Main Coronary Artery during Aortic Valve Replacement
}

\author{
Kumar Rohit, Singh Shyamveer, Mangukia Chirantan, Singh Harpreet, \\ Geelani Muhammed Abid \\ Cardiothoracic and Vascular Surgery (CTVS), G. B. Pant Hospital (GBPH), New Delhi, India \\ Email: ruborsolo@gmail.com
}

Received 26 November 2015; accepted 4 January 2016; published 7 January 2016

Copyright (C) 2016 by authors and Scientific Research Publishing Inc.

This work is licensed under the Creative Commons Attribution International License (CC BY). http://creativecommons.org/licenses/by/4.0/

(c) (i) Open Access

\section{Abstract}

This aortic valve replacement (AVR) remains the gold standard for symptomatic aortic stenosis. Peri-operative complications like dissection, stenosis involving coronary artery are well described in many series. We present a rare iatrogenic complication of disrupted left main coronary artery during the delivery of cardioplegia while performing AVR in a 54 year male patient for severe calcific aortic stenosis. The inadvertent injury to the artery was timely noticed and managed successfully with long saphenous vein graft.

\section{Keywords}

Aortic Valve Replacement, Left Main Coronary Artery, Saphenous Vein Graft

\section{Introduction}

Aortic valve replacement (AVR) is among the commonly performed open heart surgery in developing countries where rheumatic aortic valve disease still prevails. Common peri-operative complications like coronary artery obstruction, dissection and stenosis involving the coronary artery are well described in many series [1]-[3]. Here we report a rare iatrogenic complication of disrupted left main coronary artery during the delivery of cardioplegia in a patient undergoing AVR. The inadvertent injury to the artery was timely noticed and managed successfully with long saphenous vein graft.

\section{Case Report}

A 54-year-old male presented with dyspnea since 1year and syncopal attacks of 3 months duration. Pre-operative evaluation showed echocardiographic evidence of severe calcific aortic stenosis with moderate aortic regur-

How to cite this paper: Rohit, K., Shyamveer, S., Chirantan, M., Harpreet, S. and Abid, G.M. (2016) latrogenic Disruption of Left Main Coronary Artery during Aortic Valve Replacement. World Journal of Cardiovascular Surgery, 6, 1-4. 
gitation. The peak gradient across the valve was of $106 \mathrm{mmHg}$, mean gradient $56 \mathrm{mmHg}$, aortic annulus measured $2.4 \mathrm{~cm}$ and the ascending aorta was normal. Coronary angiography was normal. Patient was taken up for elective aortic valve replacement.

Through a standard median sternotomy incision patient was placed on cardiopulmonary bypass with aortic and two stage single venous cannula. With moderate hypothermia $\left(30^{\circ} \mathrm{C}-32^{\circ} \mathrm{C}\right)$ and aortic cross clamp, oblique aortotomy was performed. DLP ${ }^{\circledR}$ (Medtronic, Inc. MN, USA) antegrade cardioplegia needle with light house tip was used to deliver cardioplegia through the left coronary ostia. During delivery of cardioplegia, the line pressure was constantly monitored and maintained at 50 to 70 torr. However during delivery of cardioplegia, the left main coronary artery was seen disrupted from its origin with distal segment lying $1 \mathrm{~cm}$ away from left coronary ostium. Cardioplegia was then given through the distal segment of the injured vessel for myocardial protection. Aortic valve was excised and replaced with $23 \mathrm{~mm}$ ATS bileaflet mechanical aortic prosthesis ${ }^{\circledR}$ (ATS medical, Inc. MN, USA) using interrupted double arm pledgeted 2-0 ethibond sutures. Long saphenous vein of appropriate length was harvested from left lower limb by assistant surgeon while aortic valve prosthesis was seated. Distal end to end anastomosis of the disrupted left main coronary artery was conducted using the harvested long saphenous vein graft with 7-0 prolene suture. An additional length of long saphenous vein graft was anastomosed to the proximal left anterior descending artery using continuous 7-0 prolene as an additional graft conduit. Aortotomy incision was closed in 2 layers using 4-0 prolene suture. Following de-airing and removal of aortic cross clamp, proximal anastomosis of the two vein grafts were performed to the ascending aorta. The surgery was concluded and patient shifted on minimal inotropic support to the intensive care unit with stable vitals. The post-operative period was uneventful.

Patient was discharged on post-operative day 11 and followed up on post-operative day 18 with coronary angiography. The coronary angiography showed patent saphenous vein grafts with normal coronary vessels (Figure 1 and Figure 2). At 6 months of follow up , patient was in NYHA grade 1 and echocardiography showed marked regression of left ventricular hypertrophy with normal left ventricular function. Electrocardiogram did not reveal any abnormality.

\section{Discussion}

Complications of aortic valve replacement related to coronary artery most commonly includes occlusion of ostia due to oversized prosthesis and injury to coronary due to cannula tip or high pressure of cardioplegia but it usually result in stenosis which manifests after a few months. Literature on coronary stenosis following aortic valve replacement is enormous, Left main coronary artery is usually involved with injuries during aortic valve replacement mainly due to antegrade cardioplegia cannulae and in angiographic interventions. Left main coro-

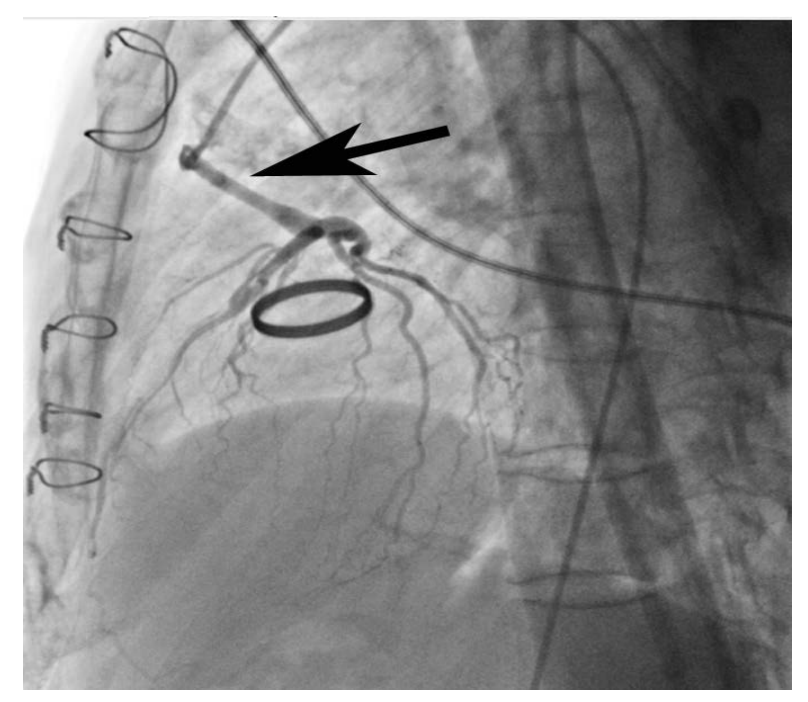

Figure 1. Coronary angiography showing patent saphenous vein graft (arrow) anastomosed to distal left main coronary artery. 


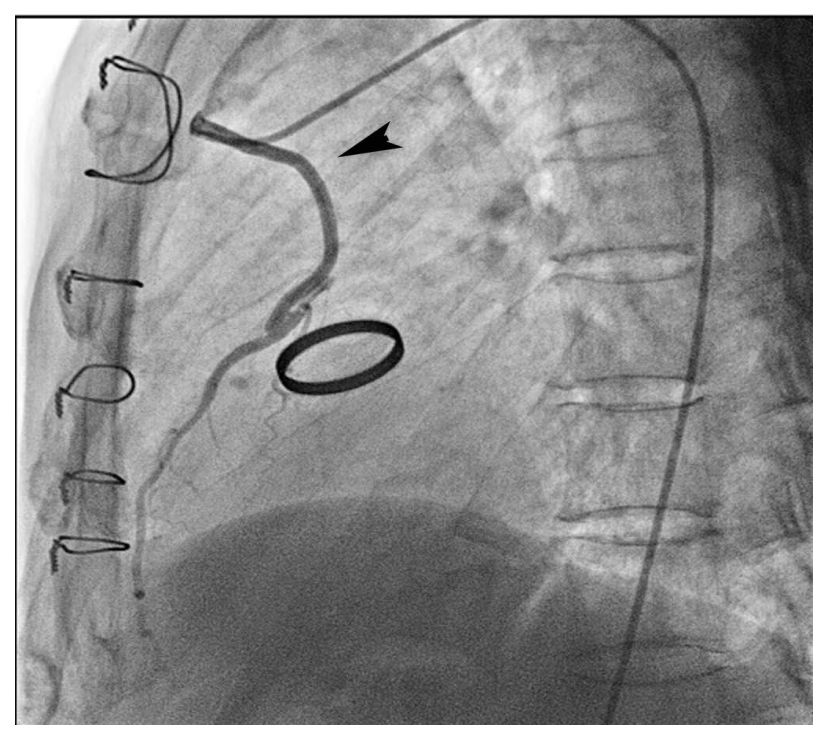

Figure 2. Coronary angiography showing saphenous vein graft (arrow) anastomosed to proximal left anterior descending coronary artery with good distal flow.

nary artery dissection and stenosis are well known, though rare iatrogenic complications [1]-[3]. Chen HM et al have recently reported an unusual case of penetrating injury to coronary artery successfully managed with primary repair [4] [5].

Coronary artery injury in such setting can be of two types mainly. 1) Direct traumatic injury; 2) Indirect jet injury.

Refined design of the modern instruments have minimized the direct injury (which generally occurs at the site of cannula insertion), but the later one is still remains a matter of concern. A minute kink in the cardioplegia cannula, high perfusion pressure and oblique course of left main artery can tremendously increase the velocity of the blood, producing jet stream. Subsequent formation of vortices exert lateral pressure on the coronaries, especially at the site of curvature and at the area of least support, producing rupture. Such lesions are relatively remote from the direct contact of the cardioplegia needle, as in our case it was $1 \mathrm{~cm}$ away.

Once the artery is found ruptured there are a few other methods to continue with cardioplegia for safer results. 1) Introduction of the cardioplegia needle from the iatrogenic opening if the opening is big enough to accommodate it; 2) retrograde cardioplegia.

If the opening is small and primary repair is feasible, retrograde cardioplegia should be given and the artery should be sutured with adequate removal of splayed margins. A smooth passage of coronary probe should be insured, in absence of which, revision of repair of graft application should be considered.

If the opening is larger and primary repair is likely to result in stenosis, reversed saphenous vein graft of left internal mammary artery should be applied to distal LAD. It is often difficult to harvest the LIMA on arrested heart because of lack of pulsatility. Moreover it may not be advisable to increase the cardioplegia time by another 20 minutes especially with hypertrophied heart of aortic stenosis. So, in our case, we quickly decided to apply a reversed saphenous vein graft.

Aortic valve replacement is one of the commonest open heart surgery performed in developing as well as developed countries and most of the iatrogenic complications remain concealed due to under reporting. Here, we report an unusual iatrogenic complication of disrupted left main coronary artery not amenable for primary repair managed successfully using long saphenous vein graft.

\section{Conclusion}

Iatrogenic left main coronary artery injury during AVR may occur away from the origin and site of contact with cardioplegia cannula. Prompt recognition, appropriate myocardial protection and timely performed revascularization is mandatory. 


\section{References}

[1] Al-Saif, S.M., Liu, M.W., Al-Mubarak, N., Agrawal, S. and Dean, L.S. (2000) Percutaneous Treatment of CatheterInduced Dissection of the Left Main Coronary Artery and Adjacent Aortic Wall: A Case Report. Catheterization and Cardiovascular Interventions, 49, 86-89. http://dx.doi.org/10.1002/(SICI)1522-726X(200001)49:1<86::AID-CCD20>3.0.CO;2-F

[2] Pande, A.K. and Gosselin, G. (1995) Iatrogenic Left Main Coronary Artery Stenosis. The Journal of Invasive Cardiology, 7, 183-187.

[3] Leontyev, S., Borger, M.A., Battellini, R., Seeburger, J., Lehmann, S., Legare, J.F. and Mohr, F.W. (2011) Embolic Occlusion of Left Main Coronary Artery Following an Isolated Aortic Valve Replacement. Journal of Cardiac Surgery, 26, 168-170. http://dx.doi.org/10.1111/j.1540-8191.2010.01189.x

[4] Chen, H.M., Chou, C.J., Shih, M.C. and Yeh, Y.S. (2011) An Unusual Fatal Penetrating Coronary Artery Injury with Effective Perioperative Management. European Journal of Cardio-Thoracic Surgery, 41, 445-447.

[5] Chavanon, O., Carrier, M., Cartier, R., Hébert, Y., Pellerin, M. and Perrault, L.P. (2002) Early Reoperation for Iatrogenic Left Main Stenosis after Aortic Valve Replacement: A Perilous Situation. Cardiovascular Surgery, 10, 256-263. http://dx.doi.org/10.1016/S0967-2109(02)00008-X 